\title{
“IMPRESSÕES" DE MÃE STELLA DE OXÓSSI, IYA ODÉ KAYODE, 5a. IYALORIXÁ DO ILÊ AXÉ OPÓ AFONJÁ, SOBRE O ATLAS GEOGRÁFICO ÁFRICABRASIL DE AUTORIA DO GEÓGRAFO RAFAEL SANZIO DOS ANJOS - UNB
}

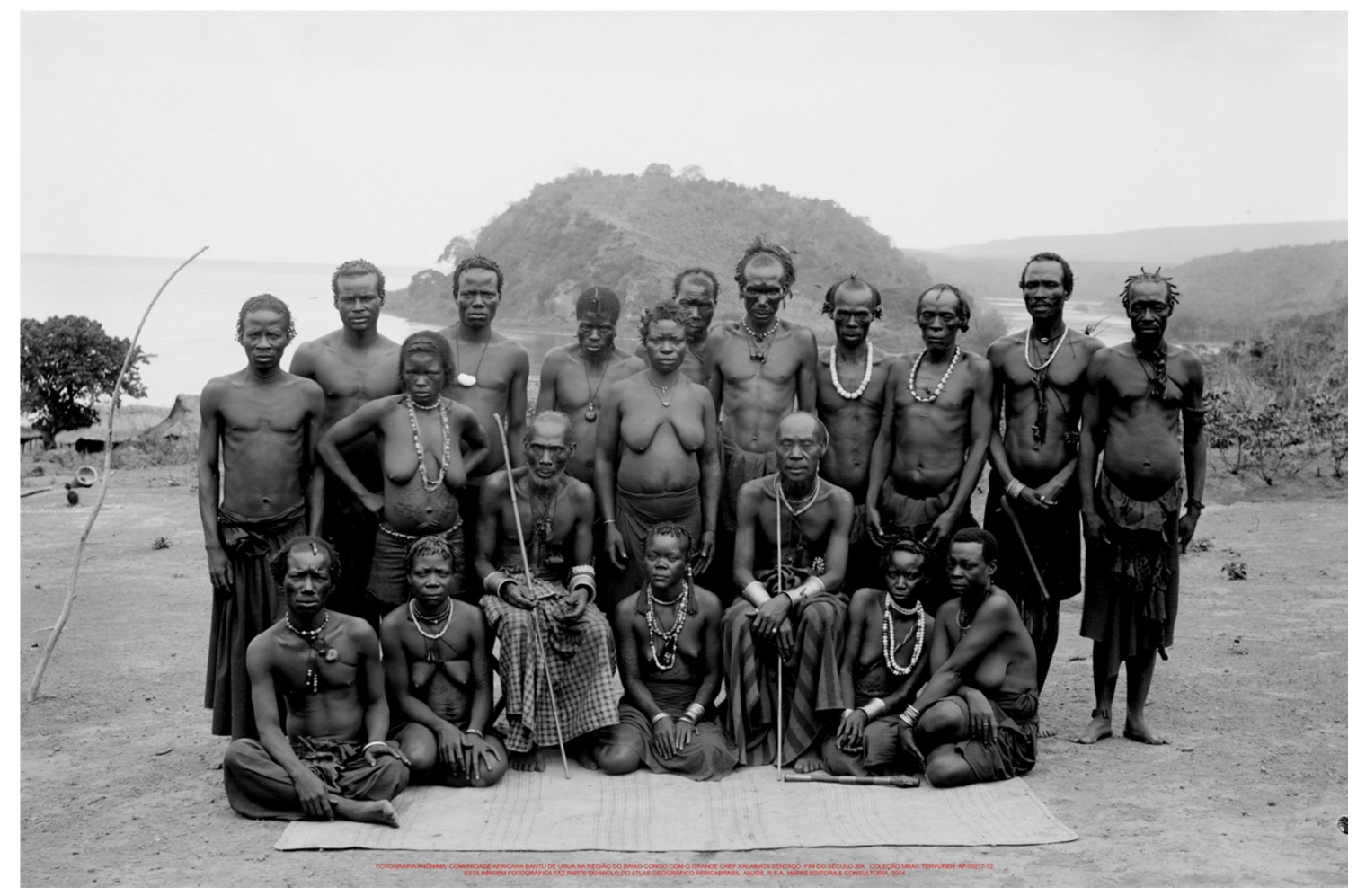

Este trabalho que chega às minhas mãos é motivo de uma grande alegria. O livro ÁfricaBrasil escrito e organizado pelo moço Rafael Sanzio, nos faz perceber a existência de uma memória que vai alem de todo conhecimento recebido na academia. Eu digo moço, porque já sou uma octogenária e tenho o prazer de encontrar muita sabedoria neste trabalho. Rafael convive com uma inspiração ancestral.

Gosto do jeito como Rafael constrói suas pesquisas. Ele vai juntando partes importantes de territórios e espaços longínquos que representam o lado negro da alma do povo brasileiro. Importante, esta transposição de imagens que lembra a nossa origem. É como uma colcha de retalhos que se juntam e nos dão a dimensão de quem somos, de onde viemos, qual o nosso papel no mundo e do que somos capazes. Esta é a África que queremos descobrir. Esta é a África que queremos conhecer. Rafael é dono de uma sensibilidade abençoada por todos os orixás.

Diante do que vejo e sinto, eu me pergunto, qual será o resultado de tudo isto no futuro? Toda vez que cada um de nós põe os joelhos no chão lembramos de pedir Revista Eletrônica: Tempo - Técnica - Território, V.5, N.1 (2014), 85:86 ISSN: 2177-4366 
Revista Eletrônica: Tempo - Técnica - Território, V.5, N.1 (2014), 85:86 ISSN: 2177-4366

bênçãos, força e boas energias também para os jovens estudiosos que podem contribuir para um mundo bem melhor.

Este é seu jeito de Rafael guerrear. Na sua cabeça há um manancial que não para de criar caminhos e mapas em movimentos. Aí está minha fé no futuro que envolve pessoas como este professor que terá por certo, muito tempo para contribuir com a educação do nosso povo.
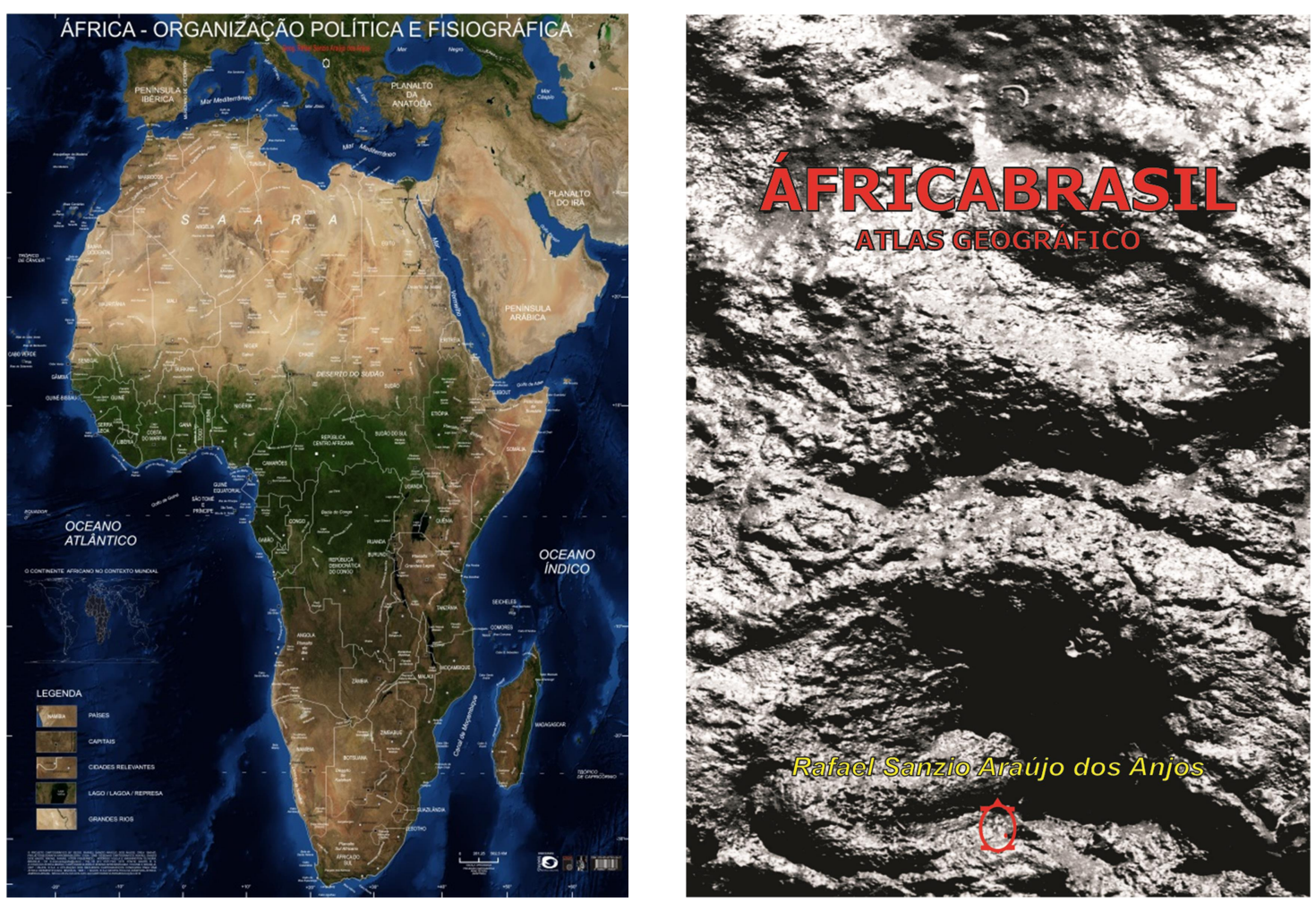

Site: $\underline{w w w . r a f a e l s a n z i o d o s a n j o s . c o m . b r}$

Link:

http://www.ciga.unb.br/index.php?option=com content \&view=article\&id=167:africab rasil $\&$ catid $=40$ :obras $-2010 \& \mid$ temid $=127$ 